\title{
Erratum to: A systematic review of the health and well-being impacts of school gardening: synthesis of quantitative and qualitative evidence
}

Heather Ohly ${ }^{1}$, Sarah Gentry², Rachel Wigglesworth ${ }^{1}$, Alison Bethel ${ }^{3}$, Rebecca Lovell ${ }^{1}$ and Ruth Garside ${ }^{1 *}$

\section{Erratum}

Following the publication of this article [1] it was brought to our attention that reference 12 was incomplete.

Reference 12 currently reads: Chiumento A. A haven of greenspace. 2012.

The completed reference should read: Chiumento A. A haven of greenspace. YoungMinds Magazine 2012;118:32-34.

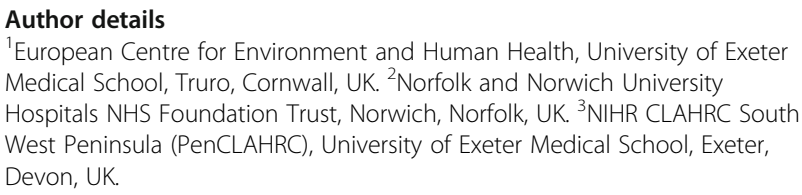

Published online: 05 October 2016

\section{Reference}

1. Ohly $\mathrm{H}$, et al. A systematic review of the health and well-being impacts of school gardening: synthesis of quantitative and qualitative evidence. BMC Public Health. 2016;16:286. doi:10.1186/s12889-016-2941-0.

\footnotetext{
* Correspondence: R.Garside@exeter.ac.uk

${ }^{1}$ European Centre for Environment and Human Health, University of Exeter Medical School, Truro, Cornwall, UK

Full list of author information is available at the end of the article
} 